\title{
An inferentialist account of students' collaboration in mathematics education
}

\author{
Abdel Seidouvy ${ }^{1}$ (D) Maike Schindler ${ }^{2}$
}

Received: 9 November 2018 / Revised: 18 April 2019 /Accepted: 23 April 2019/

Published online: 18 May 2019

(C) The Author(s) 2019

\begin{abstract}
Collaboration is an increasingly popular topic in mathematics education due to its potential to foster students' learning. The purpose of this article is to draw attention to the semantic philosophical theory of inferentialism and its value for investigating students' collaboration. We suggest that Brandom's inferentialism can serve as a valuable theoretical resource to overcome certain issues of existing theoretical viewpoints on student collaboration. In particular, we argue that inferentialism may help to understand the individual and social nature of collaboration as intertwined. We illustrate our inferentialist approach using data from two scenes taken from video-recorded group work sessions from a fifth and seventh grade primary school class in Sweden. The topic in both classes was data generation in statistics.
\end{abstract}

Keywords Collaboration $\cdot$ Data generation $\cdot$ Inferentialism $\cdot$ Norms $\cdot$ Philosophy

\section{Introduction}

In recent years, there has been an increasing interest in students' collaboration. This interest is reflected in literature by numerous studies and debates on students' collaboration when dealing with mathematical tasks (Chan and Clarke 2017; Sears and Reagin 2013). Research has found that collaboration in the mathematics classroom can be a successful approach to foster mathematics learning. A host of positive outcomes that include higher achievement (Melis et al. 2010; Oner 2016), greater effort

Abdel Seidouvy

abdel.seidouvy@oru.se

Maike Schindler

maike.schindler@uni-koeln.de

1 School of Science and Technology, Örebro University, Örebro, Sweden

2 Faculty of Human Sciences, University of Cologne, Cologne, Germany 
to learn (Yang et al. 2016), more positive relationships among students (Chaviaris and Kafoussi 2010) and more positive attitudes towards subject matter (e.g., Edwards and Jones 2003; Johnson and Johnson 1986; Rohrbeck et al. 2003; Roseth et al. 2006; Slavin 1995) have been associated with collaboration. Thus, there appears to be a consensus that collaboration should be included in classroom practices.

Research on collaboration can be broadly divided into two categories reflecting the views on collaboration. One view focuses predominantly on the investigation and evaluation of the outcomes of collaborative activity. We call this view product focused because primarily the effects of collaboration or its promoting factors are evaluated using a pre- and posttest design (e.g., Chen and Chiu 2016; Genlott and Grönlund 2016; Pea 1993; Roschelle 1992; Sears and Reagin 2013; Watson and Chick 2005). Research using the second view focuses on the collaborative process itself. Studies with this process focus investigate social interactions, communication or collective meaningmaking in students' collaboration (e.g., Dillenbourg 1999; Roschelle and Teasley 1995). However, to date, only a limited number of studies have taken a processfocused view, thus little is known about the dynamics of collaborative activity in the mathematics classroom. This constitutes a research desideratum.

One inherent difficulty of process-focused studies lies in the challenge to integrate both the individual and social facet of collaboration using one coherent theoretical framework that views these facets in their intertwined nature - not as dichotomous. Traditionally, two kinds of theories have been associated to studies with a process focus: Cognitive theories and socio-cultural theories. One main tenet of a typical cognitivist position implies that processes concerning learning can be explained by mental processes first. For this reason, a widely accepted version of cognitive theories focuses on individual phenomena and the individual mind as a unit of analysis (Taylor et al. 2017). Discourses on learning are organised around terms such as "possession", "construction", or "internalisation". Socio-cultural theories, on the other hand, emphasise the "participatory interactions that individual learners have with other individual learners, materials and representational systems within organised sociocultural structures" (Taylor et al. 2017, p. 772). One main tenet of a typical socio-cultural position implies that human learning is largely social. Thus, to learn is to become a skilled participant with a capacity to operate in a community (Sfard 1998).

In relation to the aforementioned challenge to integrate both the individual and social facet of collaboration using one coherent theoretical stance, researchers such as Bowers and Nickerson (2001), Martin et al. (2006), Martin and Towers (2003) and Stephan et al. (2003) aimed to refine and extend existing theories as lenses on both the individual and social. Other researchers have - even on a theoretical level-aimed to combine cognitivist and socio-cultural theories to account for and describe both the individual and social facet of students' collaboration. For instance, Siampou et al. (2014) used and combined Stratford et al.'s (1998) cognitive strategies for modelling with Mercer's (1995) theory on the types of interactions (disputational talk, cumulative talk and exploratory talk), reflecting cognitivist and socio-cultural perspectives to explore collaboration. However, this combination of theories has potential weaknesses. Despite the potential issue of ontological incompatibility of cognitivist and sociocultural theories, Perret-Clermont et al. (1991) stated that "research paradigms built on supposedly clear distinctions between what is social and what is cognitive will have an inherent weakness, because the causality of social and cognitive processes is, at the 
very least, circular and is perhaps even more complex" (p. 50). Furthermore, Martin et al. (2006) argued that the existing process-focused frameworks appear to lack constructs to adequately capture the dynamics of collaboration. Reflecting on the socio-cultural approach to collaboration, Martin et al. (2006) elaborated that sociomathematical norms - as put forward by Yackel and Cobb (1996) - develop and remain stable over a long period of time and, as such, cannot adequately account for the dynamics in collaboration. In this study, we present how the semantic theory of inferentialism (Brandom 1994, 2000), which was newly introduced to mathematics and statistics education, may help to overcome the social-individual dichotomy and understand the individual and social nature of collaboration as intertwined, within one theoretical perspective. We share the view of Noorloos et al. (2017) and assume that a "theory overcomes the social-individual dichotomy if it can describe the learning activity of the student simultaneously and essentially in both cognitive and social terms" (p. 441). As opposed to current theories in mathematics education, inferentialism theorises the social and individual as intertwined. Further, we will argue that inferentialism offers an evolving vocabulary which may help to capture the dynamics in collaboration.

This theoretical article outlines the philosophical background of inferentialism and presents its key concepts and their relevance to the understanding of student collaboration in mathematics and statistics education. The article is structured as follows. The first section is a brief introduction to inferentialism. The second section reports on previous research on collaboration. This section ends with a summary of ideas that are established in research on collaboration. In the following two sections, we elaborate on inferentialism as a valuable theoretical resource to explore students' collaboration. We illustrate how an inferentialist perspective helps to account for and describe collaboration in its social and individual facets. Finally, in the conclusion, we discuss the value of inferentialism for gaining new insights into collaboration as a process in the mathematics and statistics classroom.

\section{Introduction to inferentialism}

\section{What is inferentialism?}

In the present work, we draw on inferentialism as a philosophical theory and use it to understand collaboration in mathematics and statistics education. Inferentialism is one of the latest newcomers in the philosophy of language (Brandom 1994, 2000). It is a semantic, pragmatic theory that builds on philosophical ideas offered by Kant, Hegel, Frege, Wittgenstein and Sellars, among others (Brandom 1994, 2000). Inferentialism emphasises the use of language in our social practices and, particularly, the game of giving and asking for reasons (GoGAR), which for Brandom (2000) is the most fundamental linguistic activity. With the term GoGAR, Brandom accounts for a language game in which participants make claims and are responsive to reasons (see Section "The game of giving and asking for reasons" below). According to Brandom (2000), the participation in social linguistic practices is constrained by social norms, and meaning and understanding are conceptualised in terms of how well one can participate in the GoGAR. 
A considerable number of scholars have pointed out inferentialism's potential to contribute to understanding educational practices (e.g., Bakker et al. 2017; Bakker and Derry 2011; Bransen 2002; Derry 2013; Stojanov 2007). According to Dharamsi (2007) "educational practices are discursive and, as such, inferential and normative" (p. 116, emphasis in original). Additionally, Noorloos et al. (2017) argued that inferentialism holds the potential to overcome the well-known social-individual dichotomy that plagues theories and theoretical frameworks used in educational research. Yet, only few researchers in mathematics education have used inferentialism to account for student interaction or collaboration (e.g., Seidouvy, Helenius \& Schindler, in press; Schindler \& Joklitschke, 2016).

\section{The context of the empirical illustrations}

To outline the fundamental aspects of inferentialism in this article, we use data from empirical studies conducted by the first author of this article. In particular, we use three scenes that are taken from video-recorded group work sessions from a fifth grade and a seventh grade primary school class in Sweden. The fifth graders and seventh graders dealt with the frog task ${ }^{1}$ and the helicopter task ${ }^{2}$ respectively (see descriptions of the tasks below). Both tasks aimed to support students' informal inferential reasoning (IIR) based on experimentation and the topic of correlation in statistics. We used these tasks in a group work setting to encourage the students to socially discuss different aspects in the data. Our aim was to open up for a social- and content-related GoGAR. We expected the students to deal with uncertainty because measuring flying times resp. jump lengths inevitably invites students to cope with uncertainty due to measurement errors. In both studies, the students had been introduced to descriptive statistics and graphical representations of data, to the use of diagrams, and methods to calculate the mean and median before the study took place.

The classes of 18 fifth grade students and 20 seventh grade students respectively were divided into five or six groups of three to five students each, and the students were engaged in data generation in statistics. In this article, we primarily address the data generation (Cobb and McClain 2004) part of their collaborative work. Following Cobb and McClain (2004), we take data generation to mean the process that precedes data collection, which involves clarifying the significance of the phenomenon under investigation, delineating relevant aspects of the phenomenon that should be measured and considering how it should be measured.

\section{The frog task}

In the frog task, students had to experiment with paper frog models of different sizes (based on Vogel, 2009). Different-sized frogs had different colours. The frogs could be pushed down with a finger and then released to make a small jump. The task was set in a narrative where the students were called in as experts to assist a company in finding "the frog that would sell the best." This was explained to mean the frog that jumped the furthest. In the instructions, the students were asked to collaboratively test and record five jumps for each of the three frogs and then to come up with a recommendation for the company. The students had measuring tapes, the frogs and a prepared worksheet where they could record their measurements.

\footnotetext{
${ }^{1}$ This task is based on Vogel (2009).

${ }^{2}$ See Pratt (1995) for a detailed description of the task.
} 


\section{The helicopter task}

The paper helicopter task was set in a narrative similar to the frog task (based on Pratt, 1995). Here, the students were asked to find the "best rotor blade length" for paper helicopters. This was explained to mean the longest flying time. The experiment was carried out in two lessons. During the first lesson, the students collaboratively determined the flying times for different rotor blade lengths between 3 and 14 centimetres. The episode reported here is from the second lesson, where the students used the collaboratively produced data to answer three questions: (1) Which one do you think is the best rotor blade length? Explain. (2) How sure are you about it? (3) Can you find another way to decide the best rotor blade length?

\section{The social and norms}

One of Brandom's (1994) ideas is that our human society, and in particular our social practices, are permeated with normativity. That is to say that most of our activities are governed by norms. In this context, norms are reasons of a special kind, which regulate and impose constraints on our participation in social practices. Norms derive from patterns of regularities in social practices. Thus, it is also through our social practices that we establish norms. As rational beings, we are sensitive to norms, and we bind ourselves to them. Things that we do or say can be correct or incorrect; we acknowledge norms, and our claims are subject to them (Wanderer 2008). Things that we do or say can also be appropriate or inappropriate, that is, we acknowledge norms by taking a normative attitude towards them (Wanderer 2008). In line with Brandom's (1994) idea on normativity, Wanderer (2008) argues that "what makes a social interaction between beings a social practice is that it involves the exchange of socially significant performances that are governed by norms recognized in some sense by the participants" (p. 11). Thus, every norm relies on a social context.

In the following, we illustrate this sense of normativity and demonstrate inferentialist normativity in student collaboration using an example of a collaborative student activity. The scene is taken from a video-recorded group work session from the fifth graders. After the frog jumped, the students discussed how many centimetres the jump was.

\begin{tabular}{lll} 
Turn & Speaker & Utterances (gestures or pauses) \\
\hline$[1]$. & Harry & 34. \\
[2]. & Eric & Point one. \\
{$[3]$.} & Harry & Look here (pointing at the spot of the jump with his pen, in his effort to convince Eric). \\
{$[4]$.} & Eric & 34.1 (after the group went back to the spot and did a new reading). \\
{$[5]$.} & Harry & It is anyway only (showing 1 with his finger). \\
{$[6]$.} & Faye & It is 34.1. \\
{$[\ldots]$} & & (The group began organising to execute a new try). \\
{$[7]$.} & Harry & Mister (referring to the teacher), he will just laugh when he sees this. \\
{$[\ldots]$} & & (The group performed another frog jump and agrees on the length of 25.3). \\
{$[8]$.} & Harry & Mister will just laugh, 34.1 (referring to the previous measurement).
\end{tabular}


Turn Speaker Utterances (gestures or pauses)

$\begin{array}{lll}\text { [9]. } & \text { Faye } & \text { What do you mean by laugh? (surprisingly) } \\ \text { [10]. } & \text { Harry } & 1 \text { millimetre. } \\ \text { [11]. } & \text { Eric } & 1 \text { millimetre, it will make a difference. } \\ \text { [12]. } & \text { The group } & \text { (All the group members recorded } 34.1 \text { in their worksheet). }\end{array}$

To reflect on normativity, we want to draw attention to Harry and his attempt to encourage the group to ignore the actual measurement of $34.1 \mathrm{~cm}$ instead of $34 \mathrm{~cm}$. He claimed: "Mister will just laugh, 34.1," referring to the class teacher. Here, a special kind of reason, or a norm governing Harry's behaviour in this context, is the authority of the teacher. Despite the absence of the teacher, Harry seemed to draw on the teacher's authority (see Seidouvy et al. 2018). According to Harry, the teacher would have ignored one millimetre, therefore the group should do the same. Harry appeared to follow a didactic contract (Brousseau 1997), a special kind of norm, about what Harry thought the teacher would expect him and the group to say or do (Millar et al. 2001). Thus, Harry's action in this social context suggests the influence of a norm: the authority of the teacher. Here, we see how an individual commitment, and a social norm are intertwined. Further, Harry's claim is also connected to the presence of his peers. It is very unlikely that Harry would have made such claims in an out-of-school setting with people with whom he does not share the same classroom experience. The type of claims or reasons that gain authority in this particular situation depends on the context of the experiment and the people engaged in the connected social practices. So, in addition to the norm, Harry's commitment was influenced by the others.

Noorloos et al. (2017) remark that "every reason depends on a social context if it is to be uttered, or understood. There are no reasons in the absence of others with whom to discuss, share, or establish them in the first place" (p. 449). If we go back to our example, Harry and Eric's claims are highly connected to the measurement experiment and to how they should be understood. Both were responsive to the norms (reasons). Their individual claims were not separate from the social context. However, the group rejected Harry's claim. Eric's claim, "1 millimetre, it will make a difference" laid the ground for this rejection. The group followed Eric's reason during turn [12], when they all wrote down 34.1 in their worksheets. This reflects how understanding of a claim depends on the social context.

In inferentialism, individual claims are assumed to emerge in the social practices and to be shaped by the prevailing norms (see Schindler et al. 2017; Schindler and Seidouvy 2019). Reflecting on the individual and the social, Noorloos et al. (2017) conclude that "the cognitive and the social are internally related in inferentialism" (p. 449). That is, in inferentialism, the individual and social are not treated as two separated entities; instead, it is assumed that the existence of one is conditioned by the other. In placing norms (reasons of a special kind) at the heart of human experience, inferentialism can avoid the social and individual dichotomy (Noorloos et al. 2017). Further, in relation to learning (theory), Taylor et al. (2017) propose mastering as an alternative learning metaphor in inferentialism to close the epistemological gap between frameworks based on the individual-social dichotomy in mathematics education 
research. They argue that the mastering metaphor "is one according to which learners sociocognitively acquire and participate at one and the same time" (Taylor et al. 2017, p. 769, emphasis in original). From an inferentialist point of view, mathematics learning can be understood as navigating and mastering the web of reasons and actions (Bakker et al. 2017) correctly or appropriately, which, of course, depends on norms.

\section{The game of giving and asking for reasons}

One key concept in inferentialism draws on Wittgenstein's (1958) concept of a language game: the GoGAR. The GoGAR is a discursive practice in which peers exchange claims via interpretations, challenges and endorsements. It is in the GoGAR that a claim acquires its meaning or significance. Further, in the GoGAR, the meaning or significance of a claim depends on its inferential position to other claims. Thus, the significance of a claim depends on how it is interpreted, challenged or acknowledged in the GoGAR. For instance, the meaning and the significance of "it is anyway only (showing one with his finger)" depends on the previous claim " 1 millimetre, it will make a difference."

In inferentialism, claims are understood as expressions of commitments to a certain content; they are reasons which can serve as a premise and conclusion in the GoGAR. For instance, if a student says "the yellow frog is the best one," he commits himself to this belief. Such commitments are the smallest entities one can be cognitively responsible for, whereas actions are the smallest entities one can take practical responsibility for (Brandom 2000). There is no hierarchy between commitments as reasons and actions. Both reasons and actions are treated equally (Bakker et al. 2017). For instance, if students during experimentation take actions such as pointing to the yellow frog when being asked which frog is best, or showing one finger to refer to 0.1 , these actions are also expressions of their commitments and their reasons.

Finally, commitments are expressions of the prevailing norms in the social practices in which they are asserted. To Brandom (1994), giving reasons is therefore a social assessment based on what one does when one makes inferences. That is to say, giving reasons and asking for them is a social activity and is based on one's ability to use concepts in practice. The assessment of learning is to be understood as a function of how correctly or appropriately one can navigate and master the web of reasons and actions (Bakker et al. 2017), which again depends on norms. It is on these premises that we think the GoGAR, which is grounded in inferentialism (Brandom 1994), provides an instrument to coherently account for both the social, normative aspects as well as individual facets in the discursive practice.

\section{An overview of the literature}

In this section, we present an overview of the existing literature on collaboration in mathematics education. The literature can be broadly divided into two categories according to the used background theories and the viewpoints on mathematical activities. We distinguish the product-focused and process-focused view. The productfocused view is predominantly based on cognitive theories. In the product-focused view, researchers aim to evaluate the outcomes of collaboration, for example, students' performances after collaborative work. In contrast, the process-focused view puts emphasis on how collaboration takes place, for example, how students interact with 
each other. In the process-focused view, both cognitive theories and socio-cultural theories are well represented. There is, however, a slight domination of socio-cultural theories in studies with a process-focused view. In the following, we will describe the different viewpoints in detail.

In the product-focused view, researchers mostly rely on students' performances after collaborative work or use a pre- and posttest design to evaluate collaboration (Fung et al. 2018; Sinex and Chambers 2018; Wang and Hong 2018). For instance, Sun et al. (2018) used the self-regulated learning theory (Azevedo et al. 2011; Schunk and Zimmerman 2012; Winne and Hadwin 2008) to investigate the relationship between academic achievement and three key self-regulatory constructs: prior domain knowledge, self-efficacy and the use of learning strategies. The analysis of variance (ANOVA) with the results of academic achievement in both pre- and in-class of 151 students indicated that the students' self-efficacy in collaborative learning has positive outcomes on their use of help-seeking strategies during in-class learning.

Genlott and Grönlund (2016) used the socio-cultural inspired "write to learn" method to address issues related to literacy and mathematics learning among young students over a period of 3 years. The results of 502 third graders who took the Swedish National Standard Test suggested that students who used the WTL method had better test results than other groups.

Yang et al. (2016) use erroneous examples and the cognitivist-oriented concepts of students' cognitive loads (Große and Renkl 2007) and attitudes towards errors (Rybowiak et al. 1999) to assess collaboration. The test results showed that students who were engaged in collaborative learning using erroneous examples outperformed students who participated in an individual learning approach. Further, the results suggested that task complexity is also a fundamental element to enhance collaboration, regardless of the types of examples. Such findings resonated with Cohen's (1994) research, which found that a beneficial collaboration requires a sufficiently complex task that cannot easily be solved by any single individual (see also Cooper and Kagel 2005; Featherstone et al. 2011; Schwartz 1995).

Additionally, Sears and Reagin's (2013) study showed a connection between productive collaboration and task complexity (Steiner 1966; Cohen 1994) in conjunction with demonstrability (Laughlin and Ellis 1986; Steiner 1972). Their results indicated that in cases where students can successfully solve problems individually, collaboration is more of a hindrance than a benefit (Sears and Reagin 2013).

Further, Chen and Chiu (2016) created a mathematics test and metacognition scale to evaluate the influence of collaborative scripts on 80 fifth grade students. The metacognition scale is based on Pintrich et al. (1991), and Wu and Cherng's (1992) self-report instrument called motivated strategies for learning questionnaires. They reported higher mathematics achievement and better metacognitive self-regulation for the collaborative use of the scripts. Summarising the studies that used a productfocused view, it can be said that this view is dominated by a quantitative research paradigm in which conclusions are drawn based on individuals' pre- and posttest performances. Here, the social is often regarded as a collection of individuals, and statistics are used to bridge the gap between the individual and the social. That is, statistics are used to make claims about the quality of the collaboration based on individual scores. For instance, the mean score of the class is used as a measure of the group performance. 
The process-focused view brings together research that examines social interactions, discourses in students' collaboration, communication or collective meaning-making (Brenneman et al. 2019; Tabach and Schwarz 2018). In the following, we will detail the process-focused view more thoroughly, since it is of special interest for this article. In particular, we will point out what theoretical frameworks are used in the existing studies. Carlsen (2018), based on socio-cultural perspectives, used a dialogical approach (Linell 1998; Markovà 1990) to examine four upper secondary students' collaborative small-group mathematical reasoning about sinusoidal function. Although the focus of a dialogical approach in this study was on students' reasoning, it allows to draw conclusions that all the four students collaboratively contributed in various ways and to a varying degree collaboration.

Oner (2016) used Sfard's (2008) commognitive framework to trace the changes in discourses in a group of 3 eighth grade students engaged in collaborative geometrical problem-solving. The commognitive framework (Sfard 2008) in Oner's (2016) study is based on the assumptions that individuals' thinking, and in particular, their thinking about mathematical concepts, is formed by participation in particular discourses. Oner reported a significant transition in the group's discourse, from visual discourse to a "more sophisticated formal mathematical discourse" (p. 81), as a sign of a fruitful collaboration. The unit of analysis in this study was the group's discourse, and the author refrained from drawing conclusions on individual group members: "This analysis was conducted at the group unit of analysis involving the team discourse rather than the individual cognition of the students" (p. 85). Conclusions about the group do not necessarily apply consistently to the individuals in the group. The focus of Oner's study was primarily on the social facet of collaboration, whereas the individual level was not explicitly addressed or evaluated.

Mueller et al. (2012) used three models originating from discursive practice analysis in problem solving: the categories of interlocutors (Powell 2006), the idea of exploratory talks (Mercer et al. 1999) and the main notion of the mathematics classroom as a community of mathematical inquiry (Bauersfeld 1995; Forman 2003; Goos 2004). They introduced a framework involving three types of collaboration modes: co-construction, integration and modification. Coconstruction was described by Mueller and colleagues as a form of collaboration where "the argumentation is simultaneously built from the ground up," whereas integration involved instances "when a student's argument is strengthened using arguments from their peers," and modification "occurs as students attempt to correct a peer or assist him/her in making sense of a model or argument that was originally expressed in an unclear or incorrect way" (Mueller et al. 2012, p. 378). Mueller and colleagues discussed how these modes shape the mathematical argumentation of a sample of seventh graders in an informal after-school setting over a period of approximately 6 months. Based on their results, they pointed out that collaboration "involves a sharing of agency among students or peers. While engaged in exploratory talk, partners exercise agency as they challenge and defend arguments and create and evaluate hypotheses" (Mueller et al. 2012 p. 385).

Martin et al. (2006) proposed a framework similar to that of Mueller et al. (2012) based on the notion of interaction and coaction. Interaction is described as the "process of acting on the ideas of another in a reciprocal or complementary 
way," while coactions refer to the "process of acting with the ideas and actions of others in a mutual, joint way" (Martin et al. 2006, p. 156). Martin and colleagues used the framework to investigate the "nature and the form of collaboration which may (or may not) give rise to the growth of mathematical understanding at the collective level" (Martin et al. 2006 p. 156). In this framework, collective mathematical understanding is not located in the action of any single individual learner; instead, it is assumed to emerge from a combination and coaction between individual understandings. Although it cannot be claimed that the framework does not account for the individual, its focus is on the social and the growth of collective mathematical understanding.

Siampou et al. (2014) investigated students' online and face-to-face collaborations in the context of a computer-supported modelling task. Collaboration was modelled through constructs inspired by activity theory (Engeström et al. 1999) and Mercer's (1995) theory of types of interaction (i.e., disputational talk, cumulative talk and exploratory talk). Based on a mixed-methods approach, the Siampou and colleagues found that online collaboration is more productive and contributes to higher learning gain than offline, face-to-face, synchronous collaboration in modelling activities. Although the activity theory examined individuals' interactions through their use of tools, Siampou and colleagues combined it with Mercer's (1995) theory on types of interaction to address social aspects in collaboration. Thus, Siampou et al.'s (2014) framework has a social orientation.

Trubridge and Graham (2013) drew on theories of knowledge, understanding, teaching and learning in mathematics (Buxton 1978; Byers and Herscovics 1977; Hiebert and Lefevre 1986; Skemp 1976) to envisage a collaborative connected classroom model. The model was built on four key tenets: teachers' beliefs about mathematics and learning, the nature of mathematical activity, social culture of the classroom and characteristics of learners. Trubridge and Graham (2013) did not conduct an empirical study. Still, it can be said that the concept of Collaborative Connected Classroom Model (CCCM) was motivated by ideas of constructivism with emphasis on the individual learner.

Watson and Chick (2001) developed a framework to track changes in collaborative work. They went so far as to "to identify a broad framework of factors and associate them with the immediate outcomes during the group work" (Watson and Chick 2001, p. 129). The framework consisted of three collaboration outcomes in problem-solving (lifting, hovering and falling) as well as 17 factors that influence such outcomes. The factors influencing the outcome of collaborative mathematical problem solving were divided into three categories: cognitive factors, social/interpersonal factors and external factors. The same authors used the framework to investigate collaborative influences on emergent statistical thinking on the topic of data handling (Chick and Watson 2002). In that study, collaboration was evaluated by the assessment of the emergent statistical themes. Despite the multitude of factors composing the framework, including social factors, the focus on how it was used appeared to be on the individual. In the following section, we summarise our findings from the literature overview and hint at research gaps and possible future directions. 


\section{Summary, research gap and future directions}

Theories support and provide guidance on the way that researchers investigate collaboration. Summarising our brief literature overview, we found that to a large extent, theories underpinning research on collaboration focused on interaction and the use of language. This is particularly salient in the process-focused view, for instance, for Sfard's (2008) commognitive framework, Mercer's (1995) types of interaction framework, Powell's (2006) categories of interlocutor framework, Mercer et al.'s (2004) exploratory talks framework and Martin et al.'s (2006) interaction and coaction framework. Further, the process-focused view predominantly adheres to the idea of collaboration as a social phenomenon with the mathematics classroom as a community of mathematical inquiry (Bauersfeld 1995; Forman 2003; Goos 2004).

Moreover, theories that focus on individual aspects in collaboration originate from a cognitivist tradition or constructivism, for instance, Große and Renkl's (2007) cognitive loads, Wu and Cherng's (1992) metacognition scale, Hiebert and Lefevre's (1986) theory on knowledge and Skemp's (1976) theory on understanding. We also noted that quantitative methods seemed to be more frequent in the product-focused view than in the process-focused view (Brown and Lally 2018; Sun et al. 2018). In connection with quantitative research, a pre- and posttest design (as used in Yang et al. 2016) shows conditions at two points in time and infers certain development within. However, this development remains unseen. Thus, very little is exposed on the journey from the pre- to posttest or on the collaboration process itself.

To examine and evaluate collaboration as a process, there have been some studies that used at least one framework from the cognitivist perspective (individual) and one from the social perspective (e.g., Mueller et al. 2012; Oner 2016; Watson and Chick 2001). Yet, the focus in these studies was predominantly on one facet of collaboration. This suggests that the individual facet of collaboration cannot be fully investigated without taking into account the social facet and vice versa. Thus, the two perspectives are used for supportive and complementary purposes. By complementary, we mean that in most studies, the two perspectives constitute two separate parts of collaboration: on a theoretical level and in the interpretation of the data. What is often missing is an answer to the question of how social processes and cognitive processes interact and are intertwined in collaboration.

One theoretical framework closely related to what we propose is Cobb et al.'s (2001) interpretative framework. We acknowledge the valuable contribution of this framework to account for both the social and individual facet in of classroom's activities, yet, the focus of this framework is on reasoning, not on student collaboration in particular. Additionally, Cobb et al. pointed out that their "goal is not to achieve some grand theoretical synthesis" (p. 120) but that their "focus is pragmatic and centers on supporting and organizing students' mathematical learning. As a consequence, in drawing on the theoretical sources we have listed, we have adapted and modified ideas to suit our purposes" (p. 120). This means that it was not Cobb. et al's intention to develop a theorization of collaboration. However, our approach can be perceived as a step in this direction. 


\section{Proposed framework for collaboration: inspired by inferentialism}

In this section, we present an inferentialist framework to explore collaboration as a process. Our framework draws on two key concepts in inferentialism that play a fundamental role in the GoGAR: commitment and scorekeeping. We argue that through commitment and scorekeeping, inferentialism provides a new dimension to look at collaboration. It offers a vocabulary to account for the individual and the social as well as the dynamics of collaboration within one coherent framework, which may help to gain new insights into collaboration.

\section{Commitment}

A commitment is an individual claim with propositional content that one utters in discursive practices. Commitments are about one's understanding and perception of the world; they are held to be true by the person uttering them. For instance, if a student utters "the yellow frog is the best one," this is a commitment to the yellow frog. Being committed is a normative status in the sense that it is constrained by the prevailing norms in the socially shared community in which it is asserted. That is, commitments are individual, but at the same time, they reflect the social norms individuals are bound by. If the student who earlier uttered that the yellow frog is the best one then states that the red one is best, then others would probably question and challenge his new commitment because these two commitments are incompatible.

Commitments underlie all individual actions. For instance, if a student says "I cannot do this" because he is feeling that he is very bad at something (e.g., measuring lengths), he is taking responsibility for his initial commitment that he is bad at it. Further, a commitment can be challenged, rejected or acknowledged. In the case of a challenge, one may be asked to provide evidence for one's commitment. Let us go back to the interaction between Harry and Eric that was described earlier in this article. Harry's commitment to 34 centimetres was challenged by Eric. To support this commitment, Harry provided evidence, which was also a new commitment: "Mister will just laugh, 34.1." However, because Harry's evidence was not persuasive and was thus insufficient for the group (most specially for Eric), the commitment to 34 centimetres was rejected by the group. To be entitled to a commitment requires that the commitment is held to be true in the social practice in which it is asserted in accordance with the prevailing norms (of course one must hold one's own claim to be true). For instance, Eric supported his commitment to 34.1 with "1 millimetre, it will make a difference." The group (most specifically Faye) judged his evidence to be persuasive and sufficient. Accordingly, the group finally reported 34.1 to the teacher in light of Eric's evidence, which the group judged persuasive and sufficient. Note that in the inferentialist account, what is considered persuasive and sufficient falls within the competence of the members of the group and not of someone outside (e.g., the researcher).

The inferentialist concepts of commitment and inferential relation between commitments help to conceptualise collaboration. Inferential relations "are acts of the application of the norms, acts by which ... commitments and entitlements, have been instituted" (Stojanov 2007, p. 3). Thus, accounting for when and how commitments are accepted in the GoGAR can help to trace how a group maintains and synchronises reasons and actions towards what is supposedly a shared goal and how collaboration is moved by norms. 


\section{Scorekeeping}

Scorekeeping is a metaphor used in inferentialism to describe how speakers that are engaged in the GoGAR interpret and attribute commitments to others and themselves. It explains how speakers mutually assess each other for the rationality, correctness and appropriateness of their commitments while striving for the authorisation of those commitments. Each participant or speaker in the GoGAR keeps track of their own and other's commitments and evaluates how and whether each commitment is justified or can serve as evidence to support prevailing commitments. To take an example from the interaction between Harry and Eric, first, Harry committed himself to 34, secondly to "Mister will just laugh, 34.1" and then to "1 millimetre" (referring to the decimal in 34.1). In keeping track of Harry's commitments, Eric attributed a commitment to Harry's utterance " 1 millimetre": that Harry is talking about the difference between 34.1 and 34 and that Harry actually commits to the belief that they should not include/write 1 millimetre. However, Eric ruled out Harry to be entitled to 34. For Eric, the inference binding Harrys' two claims was not persuasive or sufficient, nor did it reflect the norms in this context: why should the teacher laugh if they wrote 34.1 ?

Scorekeeping is perspectival in nature in the sense that what one attributes to others and undertakes oneself is based on one's personal appreciation and understanding of the prevailing norms in the social practice or community. That is, what one attributes to others is based on one's own interpretations. Another important element in Brandom's (2000) model of scorekeeping is the concept of good moves. According to Brandom (2000), good moves are "moves that are good beyond being allowable, moves that contribute to the game being worth playing, are moves that prepare the ground for making endorsements, improve the chance of discerning commitments and allow players to gain entitlements" ( $p$. 390). Simply put, good moves are moves that contribute to making speakers' commitments explicit. Eric's commitment to "1 millimetre, it will make a difference" is a good move in relation to the context; arguably, it offers a certain explanation for Harry that what he is committed to ignoring could make a difference in the experiment.

The dynamic emergence and evaluation of commitments reflect social norms. It also helps to understand how the social norms change based on commitments which are accepted or rejected in unfamiliar situations. That is, the exploration of new areas in the space of reasons gives rise to new norms. For instance, when a group of students measures the length that a frog jumps, they may need to negotiate and establish norms or rules about how to measure, for instance, from the nose or from the furthest body part (see Seidouvy et al. in press). Norms in this sense are kinds of rules that socially emerge and regulate activities and behaviours in a group. The rules or norms regulate the social practices whilst the social practices also contribute to the evolution and establishment of new rules and norms. In this way, scorekeeping sheds light on how the intersubjectivity in participation shapes how meaning and new norms emerge, evolve and are established, in other words, the sociogenesis of norms and meanings.

\section{Illustrations}

In accordance with purposeful sampling strategies (Patton 2002), we selected one sequence from each class. Purposeful sampling is based on the assumption that the 
researcher "wants to discover, understand, and gain insight and therefore must select a sample from which the most can be learned" (Merriam 2009 p. 77).

\section{Scene 1: during the frog task}

The presented scene happened during the first frog jump measurement, which had the potential to affect the discourse in the group and, as such, may have influenced how collaboration subsequently played out in the group. Therefore, this scene could be significant to understand and gain insight into the students' collaboration. The group consisted of three girls and one boy (Alice, Christy, Jane and Bob), and the discussion in the group was centred on the unit of measurement. This scene started after Alice executed the frog jump and Christy marked the spot of the jump. However, a disagreement emerged regarding the units of measurement: 40 millimetres or 40 centimetres?

\begin{tabular}{|c|c|c|}
\hline Turn & Speaker & Utterances (gestures or pauses) \\
\hline$[1]$. & Alice: & Yes, this is centimetres. \\
\hline [2]. & Bob: & No, this is not centimetres. \\
\hline [3]. & Alice: & $\begin{array}{l}\text { Yes, this is millimetres (pointing at the measuring-tape and comparing } \\
\text { centimetre marks and millimetre marks). If this is centimetres, } \\
\text { what is this then? What is this then, if it is not centimetres? }\end{array}$ \\
\hline [4]. & Bob: & $\begin{array}{l}\text { This is } 4 \text { centimetres (taking the measuring tape and showing what } \\
\text { is actually } 40 \text { centimetres). }\end{array}$ \\
\hline$[5]$. & Alice: & No $(\ldots)$ \\
\hline$[6]$. & Jane: & This cannot be 4 centimetres. \\
\hline [7]. & Bob: & No, it is not. This is like half a meter (showing with his arms). \\
\hline [8]. & Jane: & Exactly. \\
\hline [9]. & Bob: & Ok, so it will be 40 centimetres. \\
\hline$[10]$. & Jane: & Yes, it is 40 centimetres. \\
\hline
\end{tabular}

The GoGAR in this scene involves many reasons and actions related to the unit of measurement. In particular, the inferential relations between millimetre, centimetre and metre were explored. The students evaluated and challenged each other's commitments to whether the jump length was 40 millimetres or 40 centimetres. There were a remarkable number of commitments taken. There was one asking for reason [3], which is well received in the GoGAR. Further, the GoGAR is characterised by two good moves. The first good move was in [3], where Alice asked "if this is centimetres, what is this then? What is this then, if it is not centimetres?" following Bob's commitment that it was not centimetres [2]. During turn [3], Alice expanded her initial commitment to centimetres [1] to include millimetres and to put millimetres and centimetres into a new inferential relation. This move invited Bob to revise his initial claim that it was not centimetres to "this is 4 centimetres" [4].

Here, one can see how Alice's way of pointing out the relation between centimetres and millimetres had an influence on Bob's commitments. The social affects the individual.

However, Bob's claim that "this is 4 centimetres" was immediately rejected by Alice [5], and Jane argued that it could not be 4 centimetres [6]. It is in this context that Bob makes the second good move during turn [7]: influenced by the rejection, he compares half a metre to 40 centimetres. Thus, in making new commitments in the GoGAR to 
expand upon the old commitment, the group helped Bob to discern what he was committed to and gave Bob the opportunity to revise his previous commitment from turns [2] and [4]. These good moves encouraged and helped Bob to make a new commitment [9].

The unit of measurement plays an important inferential role in this episode. The expressions centimetres, millimetres and half a metre take a pivotal position in the GoGAR as they are the key elements in Alice's and Bob's commitments. Building on reading off the measurement tape to understand the units of measurement, the GoGAR was then expanded through Bob's action in comparing 40 centimetres to half a metre. Bob's action in turn [7] created the opportunity to reconcile the perspectives in the group in terms of the commitments and the inferential relations between the commitments. Bob's commitment in turn [9] was acknowledged by Jane. In other words, Bob was entitled, or granted the right to commit, to "it will be 40 centimetres" as stated by Jane. In relation to scorekeeping, Jane added an entitlement to Bob's score. She added to Bob's score knowledge about units of measurement and the relation between millimetres, centimetres and metres (half a metre).

In sum, the episode serves to point out that inferentialism offers a lens to understand the social facet of collaboration (how students make moves in the GoGAR) and the individual facet (the students' individual claims, scores and their changes) both in a dynamic perspective, which considers the social game and its norms as well as individual scores that develop and emerge over time. In relation to the individual and social facets, this example clearly shows how the participants' commitments are related to one another. For instance, in turn [7], Bob was highly influenced by Alice in turn [3], Jane in turn [6] and the context of the experiment.

A more subtle way to understand how the social and the individual are intertwined is based on the concept of commitment that was elaborated earlier. This episode also sheds light on both the content of the collaboration (the units of measurement) and its structure (how students build up their arguments). Additionally, this episode illustrates why making inferential relations explicit is crucial in the process of converging towards a shared solution. Making inferential relations explicit allows members of the group to gain information on and about each other's commitments, and at the same time it creates opportunities for evaluation of others' and one's own commitments.

\section{Scene 2: during the helicopter task}

The following scene took place in the second lesson of the study. In this lesson, the teacher initially recalled what had happened during the first lesson. After that, she explained what would happen in the second lesson. In the following episode, the students are dealing with the second question of the task: "How sure are you about it?", referring to the groups' estimation of the best rotor blade length that they had agreed on before. The GoGAR addresses students' informal inference, in particular, their dealing with uncertainty.

\begin{tabular}{lll}
\hline Turn & Speaker & Utterances (gestures or pauses) \\
\hline$[1]$. & Katie & Hmmm ... mmm how sure are we then? We are pretty sure ... \\
{$[2]$.} & Maria & It depends on how you drop it.
\end{tabular}




\begin{tabular}{lll}
\hline Turn & Speaker & Utterances (gestures or pauses) \\
\hline$[3]$. & Katie & How sure are you about it? \\
{$[4]$.} & Anna & I am $75 \% \ldots$ no $95 \%$ sure of this. \\
{$[5]$.} & Maria & I'm less sure. So ... \\
{$[6]$.} & Katie & It depends. \\
{$[7]$.} & Anna & Like $90 \%$, because there can be a little ... \\
{$[8]$.} & Maria & We got 4 seconds on 14 centimetres and you got like .... 1. \\
{$[9]$.} & Anna & (Happy and excited) Yes, maybe $50-50$. \\
\hline
\end{tabular}

The GoGAR in this episode is different from the one in our previous illustration. The students did not explicitly refute each other's claims but instead strove to find a way to come to an agreement. The use of "we" in [1] and [8] signals that the group as a whole sought for a consensus.

In [1], Katie picked up the question for the given statistical task of how sure the students are that the chosen rotor blade length is the best one. Katie's initial claim - a first approach to address the question - was "we are pretty sure" [1]. Maria added another commitment, focusing on a physical explanation, "it depends on how you drop it" [2]. In [3], the GoGAR returned to the task, initiated by Katie's question, "how sure are you about it?" in reaction to Maria. Apparently, Katie was not satisfied by Maria's answer and was looking for more reasons. Following Katie's move, the group then engaged in a negotiation activity.

Additionally, Anna made the opening move for this negotiation, stating "I am $75 \%$... no. $95 \%$ sure of this" in [4], whereupon Maria's and Katie's commitments indicated that they disagreed with such a high confidence level ("I'm less sure"/“It depends"). This gave Anna reason to revise her initial claim and to reduce her level of confidence to 90 [7]. However, Maria still showed her concerns and uncertainty by referring to the variation in the data. Her statement "we got 4 seconds on 14 centimetres and you got like ... 1" [8] most likely referred to the flying times that they measured. Whereas one group had measured 4 seconds - an extreme value for a rotor blade length of 14 centimetres another group measured 1.86 seconds - the other extreme value for 14 centimetres. In Maria's view, the data was probably not sufficient evidence to state that 14 centimetres (the value that they chose to be best) was the best length. It is in this context that Anna then uttered "yes, maybe 50-50" [9] and appeared to be happy and excited about this.

Anna's individual utterance is deeply social. She probably used this expression to argue that both beliefs can coexist: Anna believed in a high level of confidence, whereas Maria and Katie believed that the variation did not allow for such a high level. The 50-50 reflects an attempt to reach a social agreement, such as "you are right, and I am right." Possible reasons for such an attempt might be that Anna recognised weaknesses in both arguments. The 5050 reflects her intention to overshadow the weaknesses and at the same time to share the responsibility for the group solution to the question at hand. The 50-50 seems not to refer any longer to the confidence level that the group had found the best rotor blade length. It rather appears to address the chances that the persons involved in the GoGAR are right. Anna was possibly even relieved to have found this compromise through which everyone 
could feel satisfied. The interactions in the group following this episode indicated that the group agreed with Anna's 50-50 claim.

This episode illustrates different aspects of the social and individual nature of students' collaboration. For instance, it illustrates how one student, Katie, strove to lead the GoGAR towards the topic of uncertainty. It also illustrates how Anna's score in the GoGAR progressively changed and was heavily influenced by the other students' positions and moves. If we look at how the GoGAR dealt with developing uncertainty, we find that the students first focussed on a physical explanation ("It depends on how you drop it") and then tried to grasp the uncertainty numerically by a social agreement before finally returning to an explanation based on physical properties. Through this progression, they never dealt with the uncertainty statistically. Their negotiation of uncertainty - in which they finally agreed on 50-50 (reflecting that two different perspectives may each be right) — was both individual and social. It shows how the individual commitment (50-50) is highly influenced by the social norms. Further, the episode also illustrates how, during collaboration, students may be inclined to find an agreement based on social values. In this episode, the 50-50 commitment is such a case.

Finally, this episode illustrates the difference between social agreement and shared meaning. In this case, what the students shared was the social agreement and not an agreement on a common answer. Thus, collaboration in this case was a pragmatic cooperation rather than a high level of agreement (Noorloos et al. 2017).

\section{Conclusion}

This article proposes inferentialism as a valuable theory for understanding collaboration in mathematics education research. We argued that inferentialism may help to understand the individual and the social nature of collaboration as intertwined. Inferentialism provides us with a language to account for the dynamics in collaboration while avoiding the social-individual dichotomy.

Inferentialism's emphasis on norms and its conceptualisations in commitments (and inferential relations) and scorekeeping helps to capture the process of collaboration.

We did not attempt to compare our framework with the studies combining socialoriented frameworks and individual-oriented frameworks due to space limitations. However, if the analysis in this article is correct, there is reason to believe that studies that use two separate frameworks to capture the social and the individual may overlook the intertwined nature of the social and individual in collaboration. In an inferentialist account, every individual commitment is assumed to depend on the social context in which it is put forward and understood. That is, the individual and the social are intertwined in inferentialism. Further, the relations between commitments are not given per se; they emerge in the social practice. In this perspective, inferentialism offers a powerful theoretical framework to investigate collaboration in its dynamics. Although there is much to be said on the value of networking theories, the purpose of this article was to argue that inferentialism provides opportunities to investigate collaboration as a process in one coherent framework.

Funding information This research was supported by the Swedish Research Council (project number: 2012-04811). 
Open Access This article is distributed under the terms of the Creative Commons Attribution 4.0 International License (http://creativecommons.org/licenses/by/4.0/), which permits unrestricted use, distribution, and reproduction in any medium, provided you give appropriate credit to the original author(s) and the source, provide a link to the Creative Commons license, and indicate if changes were made.

\section{References}

Azevedo, R., Johnson, A., Chauncey, A., Graesser, A., Zimmerman, B., \& Schunk, D. (2011). Use of hypermedia to assess and convey self-regulated learning. In B. J. Zimmerman \& D. H. Schunk (Eds.), Handbook of self-regulation of learning and performance (pp. 102-121). New York: Taylor \& Francis.

Bakker, A., \& Derry, J. (2011). Lessons from inferentialism for statistics education. Mathematical Thinking and Learning, 13(1/2), 5-26.

Bakker, A., Ben-Zvi, D., \& Makar, K. (2017). An inferentialist perspective on the coordination of actions and reasons involved in making a statistical inference. Mathematics Education Research Journal, 29(4), 455470.

Bauersfeld, H. (1995). "Language games" in the mathematics classroom: their function and their effects. In P. Cobb \& H. Bauersfeld (Eds.), The emergence of mathematical meaning: Interaction in classroom cultures (pp. 17-24). Hillsdale: Lawrence Erlbaum.

Bowers, J. S., \& Nickerson, S. (2001). Identifying cyclic patterns of interaction to study individual and collective learning. Mathematical Thinking and Learning, 3(1), 1-28.

Brandom, R. (1994). Making it explicit: reasoning, representing, and discursive commitment. Cambridge: Harvard University Press.

Brandom, R. (2000). Articulating reasons: an introduction to inferentialism. Cambridge: Harvard University Press.

Bransen, J. (2002). Normativity as the key to objectivity. An exploration of Robert Brandom's Articulating Reasons. Inquiry, 45(3), 373-391.

Brenneman, K., Lange, A., \& Nayfeld, I. (2019). Integrating STEM into preschool education; designing a professional development model in diverse settings. Early Childhood Education Journal, 47(1), 15-28.

Brousseau, G. (1997). Theory of didactical situations in mathematics (N. Balacheff, M. Cooper, R. Sutherland, \& V. Warfield, Trans.). Dordrecht: Kluwer Academic Publishers.

Brown, K., \& Lally, V. (2018). Rhetorical relationships with students: a higher education case study of perceptions of online assessment in mathematics. Research in Comparative and International Education, 13(1), 7-26.

Buxton, L. (1978). Four levels of understanding. Mathematics in School, 7(4), 36.

Byers, V., \& Herscovics, N. (1977). Understanding school mathematics. Mathematics Teaching, 81, $24-27$.

Carlsen, M. (2018). Upper secondary students' mathematical reasoning on a sinusoidal function. Educational Studies in Mathematics, 99(3), 277-291.

Chan, M. C. E., \& Clarke, D. (2017). Structured affordances in the use of open-ended tasks to facilitate collaborative problem solving. ZDM: The International Journal on Mathematics Education, 49(6), 951963.

Chaviaris, P., \& Kafoussi, S. (2010). Developing students' collaboration in a mathematics classroom through dramatic activities. International Electronic Journal of Mathematics Education, 5(2), 91-110.

Chen, C. H., \& Chiu, C. H. (2016). Collaboration scripts for enhancing metacognitive self-regulation and mathematics literacy. International Journal of Science and Mathematics Education, 14(2), 263-280.

Chick, H. L., \& Watson, J. M. (2002). Collaborative influences on emergent statistical thinking — a case study. The Journal of Mathematical Behavior, 21(3), 371-400.

Cobb, P., \& McClain, K. (2004). Principles of instructional design for supporting the development of students' statistical reasoning. In D. Ben-Zvi \& J. Garfield (Eds.), The challenge of developing statistical literacy, reasoning, and thinking. Dordrecht: Kluwer.

Cobb, P., Stephan, M., McClain, K., \& Gravemeijer, K. (2001). Participating in classroom mathematical practices. The Journal of the Learning Sciences, 10(1-2), 113-163.

Cohen, E. G. (1994). Restructuring the classroom: conditions for productive small groups. Review of Educational Research, 64(1), 1-35.

Cooper, D. J., \& Kagel, J. H. (2005). Are two heads better than one? Team versus individual play in signaling games. American Economic Review, 95(3), 477-509. 
Derry, J. (2013). Can inferentialism contribute to social epistemology? Journal of Philosophy of Education, $47(2), 222-235$.

Dharamsi, K. (2007). The logic of objectivity: reflections on the priority of inference. Philosophy of Education Archive, 17, 116-124.

Dillenbourg, P. (1999). Collaborative learning: cognitive and computational approaches. New York: Elsevier.

Edwards, J.-A., \& Jones, K. (2003). Co-learning in the collaborative mathematics classroom. In A. P. Koop, A. Begg, C. Breen, \& V. Santos-Wagner (Eds.), Collaboration in teacher education: Examples from the context of mathematics education (pp. 135-151). Dordrecht: Kluwer.

Engeström, Y., Miettinen, R., \& Punamäki, R. L. (Eds.). (1999). Perspectives on activity theory. Cambridge: Cambridge University Press.

Featherstone, H., Crespo, S., Jilk, L. M., Oslund, J. A., Parks, A. N., \& Wood, M. B. (2011). Smarter together! Collaboration and equity in the elementary math classroom. Reston: National Council of Teachers of Mathematics.

Forman, E. A. (2003). A sociocultural approach to mathematics reform: speaking, inscribing, and doing mathematics within communities of practice. In J. Kilpatrick, W. G. Martin, \& D. Schifter (Eds.), A research companion to principles and standards for school mathematics (pp. 333-352). Reston: National Council of Teachers of Mathematics.

Fung, D., Hung, V., \& Lui, W. M. (2018). Enhancing science learning through the introduction of effective group work in Hong Kong secondary classrooms. International Journal of Science and Mathematics Education, 16(7), 1291-1314.

Genlott, A. A., \& Grönlund, Å. (2016). Closing the gaps - improving literacy and mathematics by ICTenhanced collaboration. Computers \& Education, 99(C), 68-80.

Goos, M. (2004). Learning mathematics in a classroom community of inquiry. Journal for Research in Mathematics Education, 35(4), 258-291.

Große, C. S., \& Renkl, A. (2007). Finding and fixing errors in worked examples: can this foster learning outcomes? Learning and Instruction, 17(6), 612-634.

Hiebert, J., \& Lefevre, P. (1986). Conceptual and procedural knowledge in mathematics. In J. Hiebert (Ed.), Conceptual and procedural knowledge: the case for mathematics (pp. 1-27). Hillsdale: Lawrence Erlbaum.

Johnson, R. T., \& Johnson, D. W. (1986). Cooperative learning in the science classroom. Science and Children, 24(2), 31-32.

Laughlin, P. R., \& Ellis, A. L. (1986). Demonstrability and social combination processes on mathematical intellective tasks. Journal of Experimental Social Psychology, 22(3), 177-189.

Linell, P. (1998). Approaching dialogue. Talk, interaction and contexts in dialogical perspectives. Amsterdam: John Benjamins.

Markovà, I. (1990). Introduction. In I. Markovà \& K. Foppa (Eds.), The dynamics of dialogue (pp. 1-22). New York: Springer.

Martin, L. C., \& Towers, J. (2003). Collective mathematical understanding as an improvisational process. In N. Pateman, B. Dougherty, \& J. Zilliox (Eds.), Proceedings of the 2003 Joint Meeting of the International Group for the Psychology of Mathematics Education and the North American Chapter of International Group for the Psychology of Mathematics Education, Vol. III (pp. 245-252). Honolulu: University of Hawaii.

Martin, L., Towers, J., \& Pirie, S. (2006). Collective mathematical understanding as improvisation. Mathematical Thinking and Learning, 8(2), 149-183.

Melis, E., Sander, A., \& Tsovaltzi, D. (2010). How to support metacognitive skills for finding and correcting errors? In Paper presented at the AAAI Fall Symposium. Arlington: Cognitive and Metacognitive Educational Systems.

Mercer, N. (1995). The guided construction of knowledge: talk among teachers and learners. Clevedon. UK: Multilingual Matters.

Mercer, N., Wegerif, R., \& Dawes, L. (1999). Children's talk and the development of reasoning in the classroom. British Educational Research Journal, 25(1), 95-111.

Mercer, N., Littleton, K., \& Wegerif, R. (2004). Methods for studying the processes of interaction and collaborative activity in computer-based educational activities. Technology, Pedagogy and Education, 13(2), 195-212.

Merriam, S. B. (2009). Qualitative research: A guide to design and implementation (3rd ed). San Francisco, CA: Jossey-Bass.

Millar, R., Leach, J., \& Osborne, J. (2001). Improving science education: the contribution of research. Buckingham: Open University Press. 
Mueller, M., Yankelewitz, D., \& Maher, C. (2012). A framework for analyzing the collaborative construction of arguments and its interplay with agency. Educational Studies in Mathematics, 80(3), 369-387.

Noorloos, R., Taylor, S. D., Bakker, A., \& Derry, J. (2017). Inferentialism as an alternative to socioconstructivism in mathematics education. Mathematics Education Research Journal, 29(4), 437453.

Oner, D. (2016). Tracing the change in discourse in a collaborative dynamic geometry environment: from visual to more mathematical. International Journal of Computer Supported Collaborative Learning, $11(1), 59-88$.

Patton, M. Q. (2002). Qualitative research \& evaluation methods (Vol. 3). London: SAGE.

Pea, R. D. (1993). Learning scientific concepts through material and social activities: conversational analysis meets conceptual change. Educational Psychologist, 28(3), 265-277.

Perret-Clermont, A.-N., Perret, J.-F., \& Bell, N. (1991). The social construction of meaning and cognitive activity in elementary school children. In L. Resnick, J. Levine, \& S. Teasley (Eds.), Perspectives on Socially Shared Cognition (pp. 41-62). Hyattsville: American Psychological Association.

Pintrich, P. R., Smith, D. A. F., Garcia, T., \& McKeachie, W. (1991). A manual for the use of the motivated strategies for learning questionnaire (MSLQ). Ann Arbor: University of Michigan, National Center for Research to Improve Postsecondary Teaching and Learning.

Powell, A. (2006). Social cognition emerging from student-to-student discursive interactions during mathematical problem solving. In J. Novotná, H. Moraová, M. Krátká, \& N. Stehlíková (Eds.), Proceedings of the 30th Conference of the International Group for the Psychology of Mathematics Education, Vol. 4 (pp. 361-368). Morelia: Michoacan University of Saint Nicholas of Hidalgo.

Pratt, D. (1995). Young children's active and passive graphing. Journal of Computer Assisted Learning, 11(3), $157-169$.

Rohrbeck, C. A., Ginsburg-Block, M. D., Fantuzzo, J. W., \& Miller, T. R. (2003). Peerassisted learning interventions with elementary school students: a meta-analytic review. Journal of Educational Psychology, 94(2), 240-257.

Roschelle, J. (1992). Learning by collaborating: convergent conceptual change. The Journal of the Learning Sciences, 2(3), 235-276.

Roschelle, J., \& Teasley, S. D. (1995). The construction of shared knowledge in collaborative problem solving. In C. O’Malley (Ed.), Computer supported collaborative learning (pp. 69-97). Berlin: Springer.

Roseth, C. J., Fang, F., Johnson, D. W., \& Johnson, R. T. (2006). Meeting early adolescents' developmental needs: A meta-analysis of the effects of cooperative, competitive, and individualistic goal structures. Paper presented at AERA Annual Meeting, San Francisco.

Rybowiak, V., Garst, H., Frese, M., \& Batinic, B. (1999). Error orientation questionnaire (EOQ): reliability, validity, and different language equivalence. Journal of Organizational Behavior, 20(4), 527-547.

Schindler, M., \& Seidouvy, A. (2019). Informal inferential reasoning and the social: understanding students' informal inferences through an inferentialist epistemology. In D. Ben-Zvi \& G. Burrill (Eds.), Topics and trends in current statistics education research: International perspectives (pp. 153-171). New York: Springer.

Schindler, M., Hußmann, S., Nilsson, P., \& Bakker, A. (2017). Sixth-grade students' reasoning on the order relation of integers as influenced by prior experience: an inferentialist analysis. Mathematics Education Research Journal, 29(4), 471-492.

Schindler, M., \& Joklitschke, J. (2016). Designing tasks for mathematically talented students. In K. Krainer \& N. Vondrová (Eds.), Proceedings of the Ninth Congress of the European Society for Research in Mathematics Education (CERME 9) , 1066-1072. https://hal.archives-ouvertes.fr/hal-01287313 /document. Accessed 6 May 2019.

Schunk, D. H., \& Zimmerman, B. J. (Eds.). (2012). Motivation and self-regulated learning: Theory, research, and applications. Oxford: Routledge.

Schwartz, D. L. (1995). The emergence of abstract representations in dyad problem solving. The Journal of the Learning Sciences, 4(3), 321-354.

Sears, D. A., \& Reagin, J. M. (2013). Individual versus collaborative problem solving: divergent outcomes depending on task complexity. Instructional Science, 41(6), 1153-1172.

Seidouvy, A., Helenius, O., \& Schindler, M. (2018). Data generation in statistics - both procedural and conceptual. An inferentialist analysis. In J. Häggström, Y. Liljekvist, J. Bergman Ärlebäck, M. Fahlgren, \& O. Olande (Eds.), Perspectives on professional development of mathematics teachers. Proceedings of MADIF 11 (pp. 191-200). Gothenburg, SMDF/NCM.

Seidouvy, A., Helenius, O., Schindler, M. (in press). Authority in students' peer collaboration in statistics. An empirical study based on inferentialism. Nordic Studies in Mathematics Education. 
Sfard, A. (1998). On two metaphors for learning and the dangers of choosing just one. Educational Researcher, 27(2), 4-13.

Sfard, A. (2008). Thinking as communicating: human development, the growth of discourses, and mathematizing. Cambridge: Cambridge University Press.

Siampou, F., Komis, V., \& Tselios, N. (2014). Online versus face-to-face collaboration in the context of a computer-supported modeling task. Computers in Human Behavior, 37(0), 369-376.

Sinex, S. A., \& Chambers, T. L. (2018). Discovering pi and its measurement variation: a collaborative cloud activity. Spreadsheets in Education (eJSiE), 10(3), 4.

Skemp, R. R. (1976). Relational understanding and instrumental understanding. Mathematics Teaching, 77(1), 20-26.

Slavin, R. (1995). Enhancing intergroup relations in schools: cooperative learning and other strategies. In W. Hawley \& A. Jackson (Eds.), Toward a common destiny: Improving race and ethnic relations (pp. 291314). San Francisco: Jossey Bass.

Steiner, I. D. (1966). Models for inferring relationships between group size and potential group productivity. Behavioral Science, 11(4), 273-283.

Steiner, I. D. (1972). Group process and productivity. New York: Academic Press.

Stephan, M., Cobb, P., \& Gravemeijer, K. (2003). Chapter 5: coordinating social and individual analyses: learning as participation in mathematical practices. Journal for Research in Mathematics Education. Monograph, 12, 67-102.

Stojanov, K. (2007). Bildung as deontic scorekeeping? Toward a social-pragmatist approach in educational theory. Papers of the Annual Conference of the Society for Philosophy of Education of Great Britain.

Stratford, S. J., Krajcik, J., \& Soloway, E. (1998). Secondary students' dynamic modeling processes: analyzing, reasoning about, synthesizing, and testing models of stream ecosystems. Journal of Science Education and Technology, 7(3), 215-234.

Sun, Z., Xie, K., \& Anderman, L. H. (2018). The role of self-regulated learning in students' success in flipped undergraduate math courses. Internet and Higher Education, 36(1), 41-53.

Tabach, M., \& Schwarz, B. B. (2018). Professional development of mathematics teachers toward the facilitation of small-group collaboration. Educational Studies in Mathematics, 97(3), 273-298.

Taylor, S. D., Noorloos, R., \& Bakker, A. (2017). Mastering as an inferentialist alternative to the acquisition and participation metaphors for learning. Journal of Philosophy of Education, 51(4), 769-784.

Trubridge, N., \& Graham, T. (2013). Exploring the features of a collaborative connected classroom. Proceedings of the British Society for Research into Learning Mathematics, 33(2), 49-54.

Vogel, M. (2009). Experimentieren mit Papierfröschen [Experimenting with paper frogs]. Praxis der Mathematik in der Schule, 51(26), 22-30.

Wanderer, J. (2008). Robert Brandom. Stockfield: Acumen.

Wang, S. L., \& Hong, H. T. (2018). The roles of collective task value and collaborative behaviors in collaborative performance through collaborative creation in CSCL. Educational Technology Research and Development, 66(4), 937-953.

Watson, J. M., \& Chick, H. L. (2001). A matter of perspective: views of collaborative work in data handling. In M. van den Heuvel-Panhuizen (Ed.), Proceedings of the 25th conference of the International Group for the Psychology of Mathematics Education (Vol. 4, pp. 407-414). Utrecht, NL: Freudenthal Institute.

Watson, J. M., \& Chick, H. L. (2005). Collaborative statistical investigations in diverse settings. International Journal of Mathematical Education in Science and Technology, 36(6), 573-600.

Winne, P. H., \& Hadwin, A. F. (2008). The weave of motivation and selfregulated learning. In D. H. Schunk \& B. J. Zimmerman (Eds.), Motivation and self-regulated learning: Theory, research, and applications (pp. 297-314). Mahwah: Lawrence Erlbaum.

Wittgenstein, L. (1958). Philosophical investigations. Basil Blackwell.

Wu, J. J., \& Cherng, B. L. (1992). Motivated strategies for learning questionnaire (MSLQ): a revised version for use with Chinese elementary and junior high school students. Psychological Testing, 39, 59-78.

Yackel, E., \& Cobb, P. (1996). Sociomathematical norms, argumentation, and autonomy in mathematics. Journal for Research in Mathematics Education, 27(4), 458-477.

Yang, Z. K., Wang, M., Cheng, H. N., Liu, S. Y., Liu, L., \& Chan, T. W. (2016). The effects of learning from correct and erroneous examples in individual and collaborative settings. The Asia-Pacific Education Researcher, 25(2), 219-227.

Publisher's note Springer Nature remains neutral with regard to jurisdictional claims in published maps and institutional affiliations. 